Misra, S. N. 1971. Chemical distinction of high-grade ortho- and para-metabasites. Norsk. geol. Tidsskr. 51, 311-16.

Miyashiro, A. 1968. Metamorphism of mafic rocks. In: Basalts, vol. 2, pp. 799-834. Interscience, New York.

Poldervaart, A. 1953. Metamorphism of basaltic rock: a review. Bull. geol. Soc. Am. 64, 259-74.

Rice, C. M. 1946. Dictionary of Geological Terms. Edwards, Michigan.

Sederholm, J. J. 1907. On granite and gneiss. Bull. Commn géol. Finl. 23.

Department of Geology

R. B. ELLIOTT

University of Nottingham

Nottingham

16th July 1973

\title{
Observations on the Kaiserstuhl Loess
}

\section{(Plates 1-3)}

SIR,- - In the recent paper by Smalley, Krinsley \& Vita-Finzi (1973) it is contended that the Kaiserstuhl loess was derived from glacially-ground material. Evidence from scanning electron microscope examination of quartz particles is given to support this. While it is not disputed that such grinding can take place and that this may ultimately give rise to loessic deposits, this is certainly not the only possible origin. This is accepted by these authors, though they attribute most of the debris to glacial grinding.

I have been investigating some morainic deposits and related glaciers in Saastal, Switzerland (Kanton Wallis), for several years. This area lies to the $\mathbf{N}$ of the main Alpine Watershed and may have contributed material to the circum-Alpine loesses. The study includes scanning electron microscopic examination of quartz grains from various environments. I would like to make two points regarding the origin of (European) loess deposits and the interpretation given by Smalley, Krinsley \& Vita-Finzi.

(1) Most of the morainic material in the Alps consists of material which has been extra-glacially derived; that is, it has fallen from the cliffs and mountain sides or been swept there by various processes, transported on a glacier surface and then dumped as a moraine ridge or a thin veneer on valley floors. In a sense, therefore, this material is 'glacial' yet it has not been subglacially ground. The glacier surface is a very effective transporting medium and though it may take some time, there is generally no restriction, other than climatic, on how far and how much debris can be transported by the glacier. In temperate glaciers, such as are in the Alps, there is very little subglacially transported material between the ice and the bedrock or debris frozen within the ice at the glacier sole. However, there is material which has become englacial by falling on to the glacier surface in the accumulation area; though this volume is slight compared with present day supra-glacial loads, it may constitute a considerable total over a period of time. One difficulty which hampers all estimates of glacial erosion (sensu stricto, i.e. subglacial processes) is knowing how much the originally extra-glacial material contributed to the actual volumes measured in any situation.

Unfortunately, examination of quartz grains by scanning electron microscopy is not much help. Supra-glacial material can look similar to that shown in Smalley, Krinsley \& Vita-Finzi (1973, plate 1) and so can quartz grains from subglacial and en-glacial positions! Furthermore, supra-glacial grains may have some surface weathering and lightly cemented debris. Plate $1(a)$ shows a supra-glacial grain from Feegletscher, Switzerland. Quartz redeposition can be seen together with some other debris. Present-day weathered material on cliffs also shows a wide variety of quartz redeposition though generally the surfaces were fairly clean after preparation. What does remain on the surface (after 5 minutes of boiling in $35 \%$ nitric acid) is not so much comminution 
debris from grinding but rather the quartz which has come from that particular surface of the grain. The flat flakes are thought to be related to quartz cleavages and may be attached to the surface by Van der Waals forces or by cementation. These cleavage fiakes can be produced by crushing - a process which operates when material falls down cliffs and also in moraines themselves due to overburden pressures. Cementation of various flakes and particles, both quartz and other comminution debris, can also apparently occur in large moraines and experiments are underway to test this. It is possible that the eolian removal of such grains (see below) could account for the debris seen on some loess particles.

The amount of precipitation on older moraine material than the present is also variable. Plate $1(b)$ shows a grain from a moraine formed by dumping of supra-glacial material. The date of the moraine is not positively known but is probably older than 1000 B.P. This shows features similar to other extra-glacially derived quartz grains from this and other zones. For comparison, Plate $2(a)$ shows a grain deposited on a moraine ridge $c$. A.D. 1890. The flat 'cleavage face' can be compared with Smalley et al. (1973, plate 2). Plate $2(b)$ shows a grain from a frontal deposit which may have fallen from the glacier snout and thus given rise to the breakage fractures seen. The moraine in this case dates from $c$. A.D. 1940.

(2) Material both on the cliff faces and in the moraines has an extra-glacial origin ultimately. The smaller particles are frequently removed from these positions by wind action, a process which can be seen today. Plate $3(a, b)$ shows grains from a snowbank surface collected several hundred metres away from the moraine face. It shows characteristics which have been called 'glacial' but is also typical of quartz grains from the moraine. Small dust storms can occur at any time of the year and the material can be seen in clouds in the main valley from time to time. Muller-Beck (1968) notes that up to the last century a 'typical loess' was brought by Föhn winds from the S, depositing up to $30 \mathrm{~mm}$ in one year. These winds could have brought material from the Italian side of the Alpine Watershed as well as from, for example, the Feegletscher area. Moraines which are devoid of vegetation provide plentiful debris of this kind, especially as they dry after snowmelt. A vertical section of a snowbank in spring usually shows several of these layers. When the particular sample examined was collected, the whole of the glacier area was covered with snow and the only bare area was the proximal moraine face.

Though the Pleistocene ice sheets covered a much larger area of the rock than they do at present, there must have been very long periods when there were situations analogous to that today. There is some evidence from my own work that rates of alpine extra-glacial denudation have been much greater in the past than at present (see also Rapp, 1960; Grove, 1972). This denudation is a potential source for large amounts of loessic material which has not been subglacially ground. These processes - rockfalls, debris falls, landslides, etc. - are high-energy situations which could give breakage fracture patterns on quartz grains.

All these factors add up to a situation where extra-glacial sources of material for loess must be considered - at least in Alpine areas. In effect, this just means that there must be an extra branch to denote this in the model proposed by Smalley et al. (1973).

The nature of the glacially transported debris from Pleistocene glaciers advancing from the $\mathbf{N}$ is a more difficult problem. Nevertheless, it is possible that this material too may not be ground by glacier ice. Frequently, till is locally derived by incorporation of pre-weathered material. There is evidence from samples I have investigated and also by Brown (1973) that inherited surface texture characteristics (i.e. those produced in the source rock), found, for example, on cliffs and other weathered material, are similar to surface textures which have frequently been called 'glacial'.

Hence, despite the examination of a large number of quartz grains, it has been found that scanning electron microscope examination cannot discriminate between some subenvironments in glacierized areas. The exact nature of the origin of some loess deposits therefore remains indeterminate by this method. Cliffs and non-glacierized mountains may be provenance areas for material to be transported by the wind. In the Pleistocene there is a reasonable relationship: mountains $=$ glacier proximity $=$ loess parent material; but this is not the same as saying: loessic material = glacial grinding. 
There are further implications for both the scanning electron microscope examination of glacial and extra-glacial quartz grains as well as the provenance of 'glacial' material (Warnke, 1970) which need more intensive investigation.

I would like to thank Mr D. Gray, Department of Metallurgy and Materials Science, University of Cambridge and Dr H.-U. Nissen and Fr P. Jemelka of the Labor für Elektronenmikroskopie, Aussenstation Hönggerberg, ETH, Zürich, for assistance with their scanning electron microscopes.

\section{References}

Brown, J. E. 1973. Depositional histories of sand grain textures. Nature, Lond. 242, 396-8.

Grove, J. M. 1972. The incidence of landslides avalanches, and floods in western Norway during the Little Ice Age. Arctic Alp. Res. 4, 131-8.

Muller-Beck, H.-J. 1968. Loess sediments in Switzerland. In Schultz, C. B. \& Frye, J. C. (eds): Loess and related eolian deposits of the world. Proc. 7th Int. Ass. Quat. Res. 12, 343-4.

Rapp, A. 1960. Talus slopes and mountain walls at Tempelfjorden, Spitsbergen. Skr. norsk Polarinst. 119, 96 pp., 20 pls.

Smalley, I. J., Krinsley, D. H. \& Vita-Finzi, C. 1973. Observations on the Kaiserstuhl loess. Geol. Mag. 110, 29-36.

Warnke, D. A. 1970. Glacial erosion, ice rafting, and glacial marine sediments: Antarctic and the Southern Ocean. Am. J. Sci. 269, 276-94.

Geography Department

W. BRIAN WHALLEY

Swiss Federal Institute of Technology

Sonneggstrasse 5

8006 Zürich

Switzerland

9th July 1973

\section{EXPLANATION OF PLATES}

Plate $1(a)$. Supra-glacial grain with conchoical fractures and some chipping and blunting on the edges. Silica redeposition on facets and in hollows. The smaller $(<5 \mu \mathrm{m})$ particles are almost all quartz, the larger flakes are quartz and feldspars.

Plate $1(b)$. Quartz grain from a moraine (c. 1000 B.P.) dumped from a glacier surface. The stepped fracture surfaces are becoming covered with redeposited silica with more extensive growth on other faces.

Plate 2(a). Grain from a moraine deposited from the glacier surface c. A.D. 1890. Quartz cleavage flakes and precipitation platelets at $c$. There is virtually no chipping of the pronounced edges or any blunting by precipitation of silica at this stage. The larger flakes are quartz, feldspars and micas.

Plate 2(b). Recent (c. A.D. 1940) frontal deposit. Fracture surfaces can be seen and the edges do not have silica redeposition. There are some very small quartz cleavage flakes on the surface together with larger particles of quartz and feldspar, bottom right, which were not washed off in preparation.

Plate 3(a). Grain from a snowbank surface collected Easter 1973 but which has originally come from the moraine surface. A very angular grain with high surface relief, stepped fracture surfaces and comminution debris.

Plate $3(b)$, Grain with the same origin as $3(a)$. The edges are still sharp but chemical etching and redeposition of silica has modified the surface. 
Geol. Mag. Vol. 111, 1974, Whalley, Plates 1-3, between pp. 86 and 87.

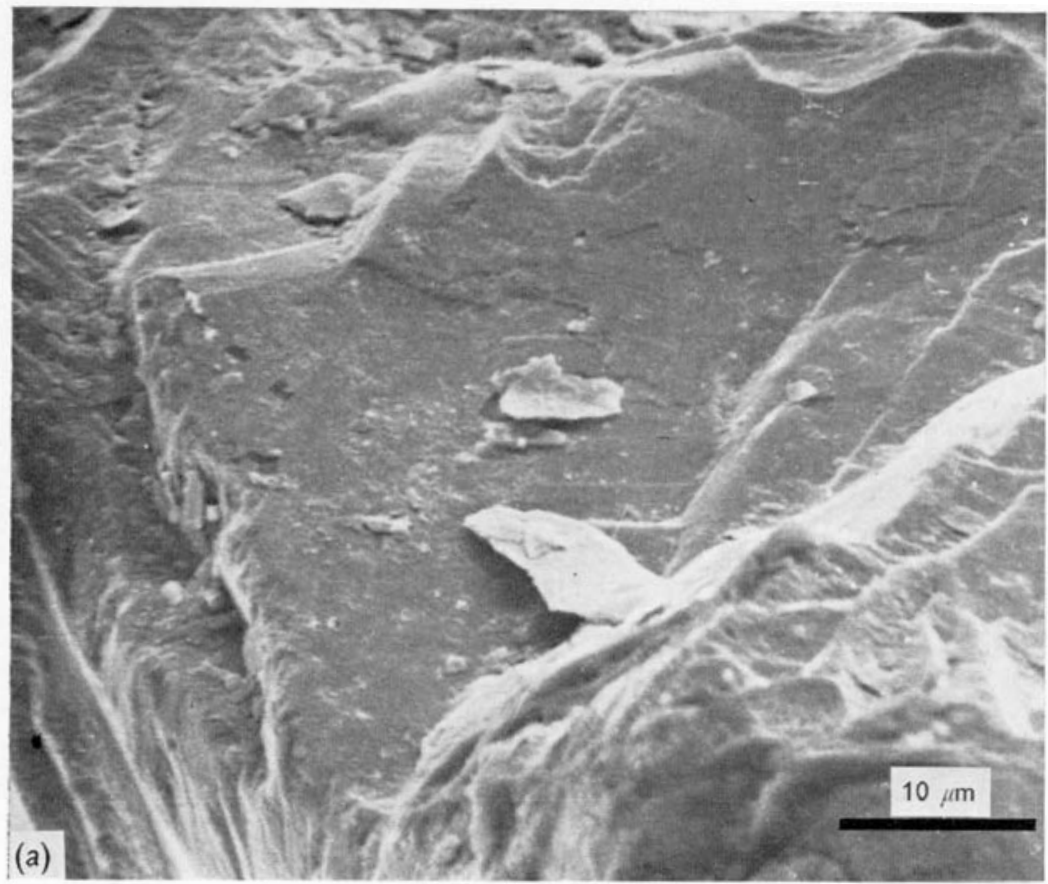

Plate 1(a). Supra-glacial grain.

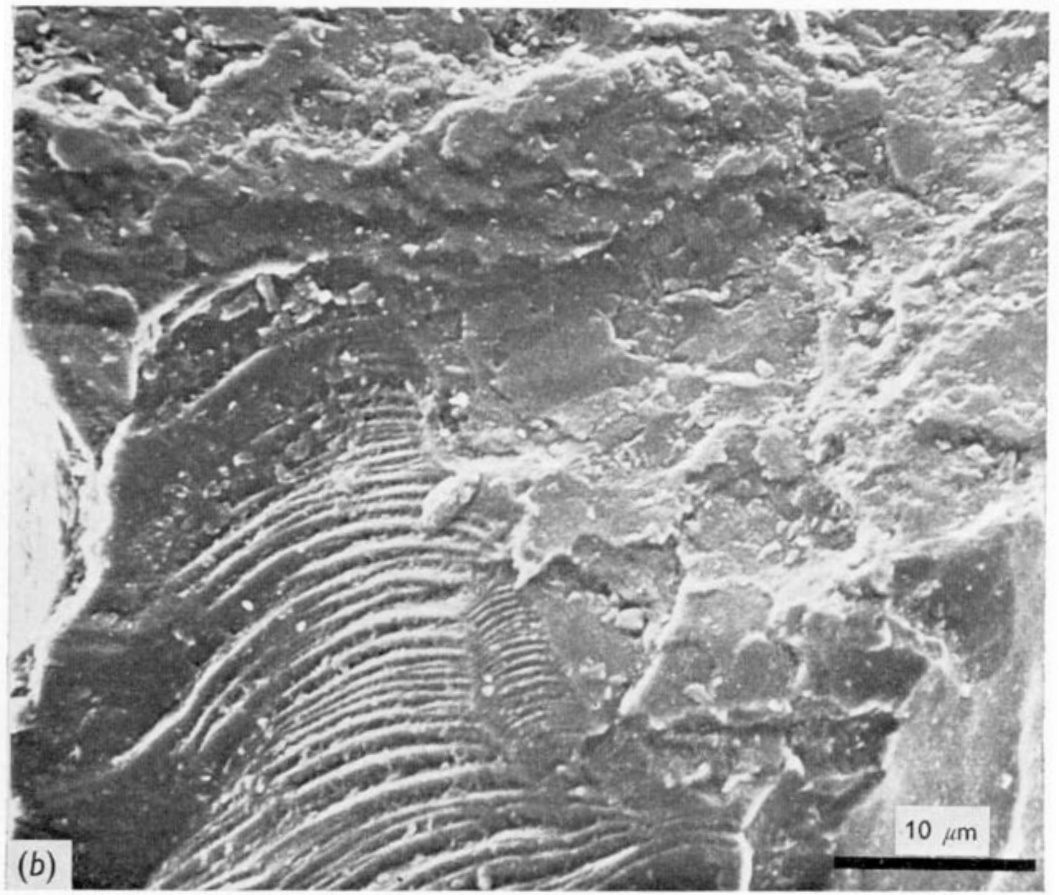

Plate $1(b)$. Quartz grain from a moraine. 
Geol. Mág. Vờ. 11i, 1974, Whaliey, Plate 2.

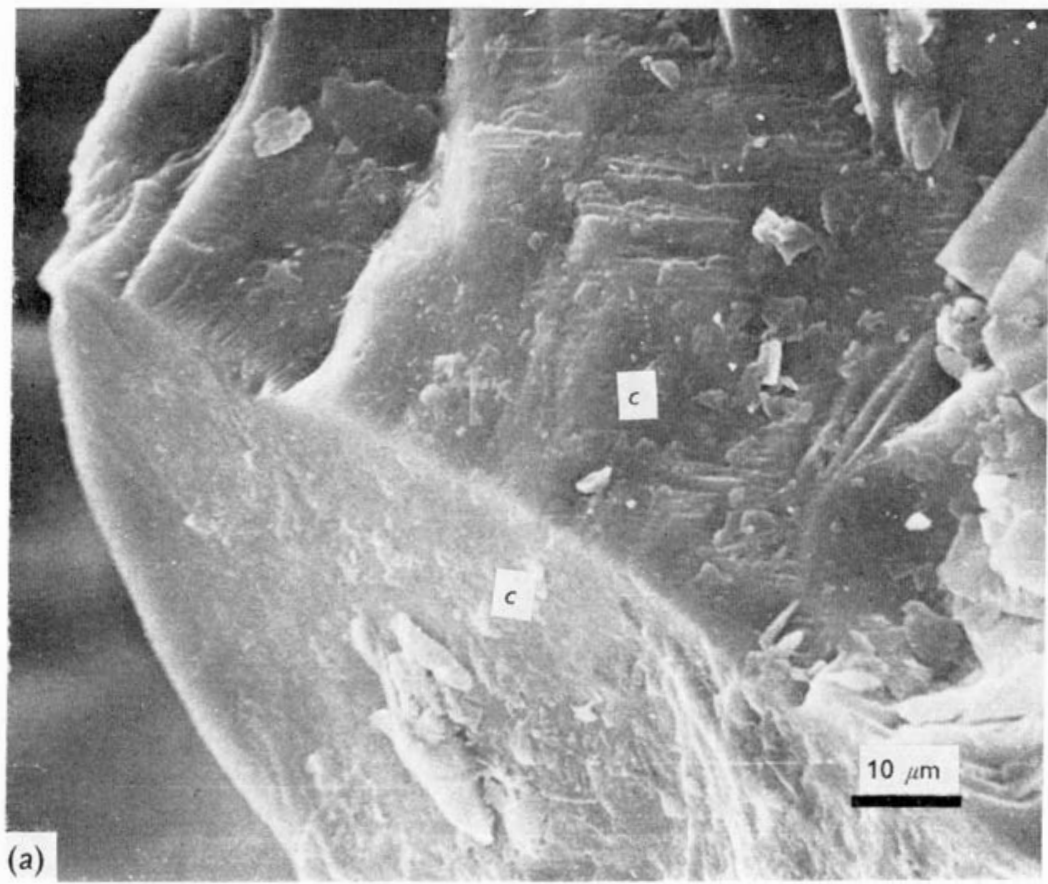

Plate 2(a). Grain from a moraine.

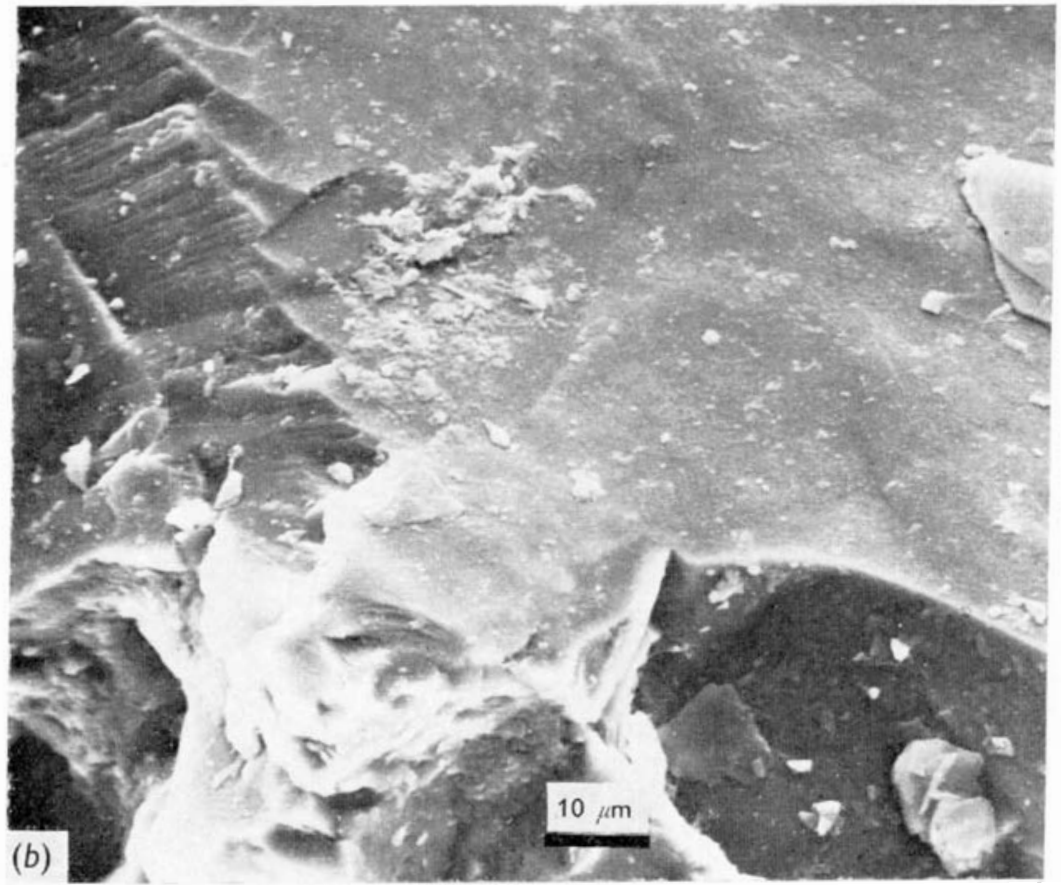

Plate 2(b). Recent frontal deposit (c. A.D. 1940). 
Geol. Mag. Vol. 111, 1974, Whalley, Plate 3.

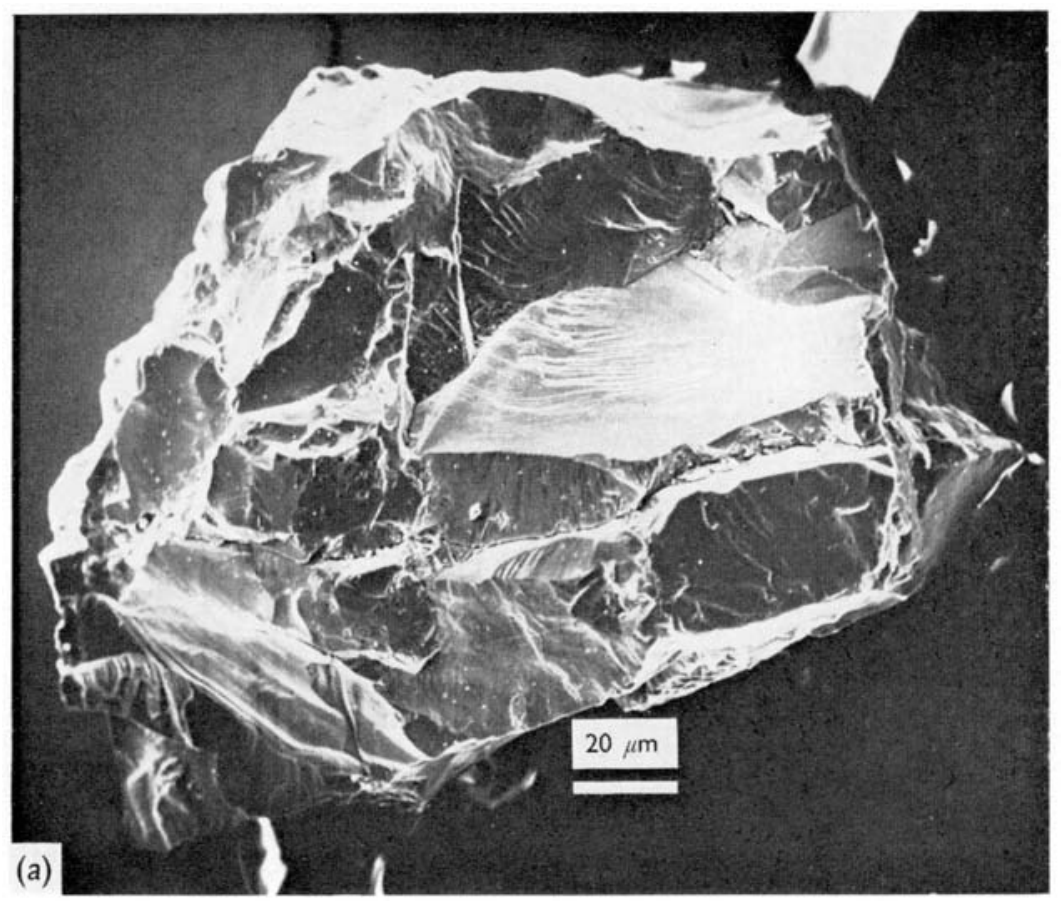

Plate 3(a). Grain from snowbank surface (1973).

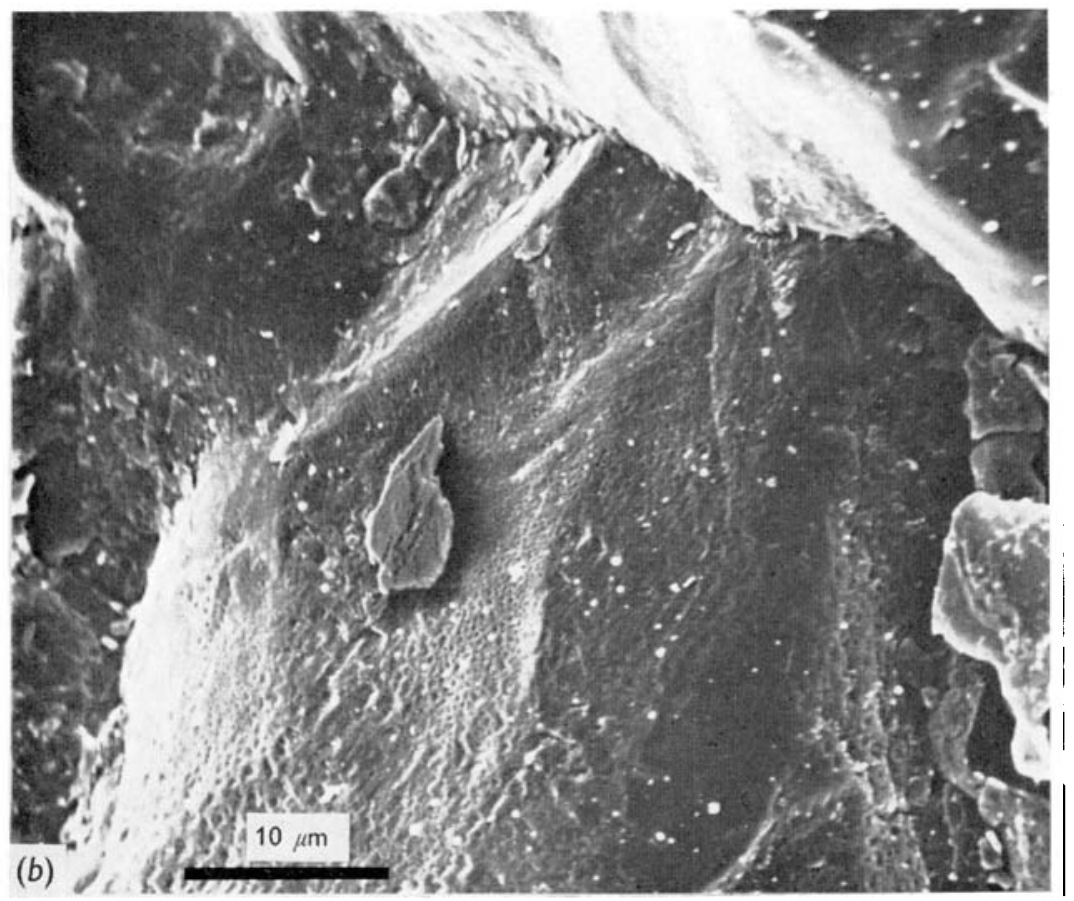

Plate $3(b)$. Grain from same origin as $3(a)$ above. 